\section{Condições sociodemográficas de crianças de zero a dois anos filhas de mães com HIV/Aids, Fortaleza, CE, Brasil}

\section{The socio-demographic conditions of children aged 0 to 2 years born to mothers with HIVIAIDS, in the city of Fortaleza, in the Brazilian State of Ceará}

Márcia Maria Tavares Machado 1 Marli Teresinha Gimeniz Galvão 2

Ana Cristina Lindsay 3 Antonio José Ledo Alves da Cunha 4 Álvaro Jorge Madeiro Leite 5 Robério Dias Leite 6 Ligia Regina Franco Sansigolo Kerr 7

1,7 Departamento de Saúde Comunitária. Faculdade de Medicina. Universidade Federal do Ceará. Rua Professor Costa Mendes, $1608,5^{\circ}$ andar. Bairro Rodolfo Teófilo. Fortaleza, CE, Brasil. CEP: 60.430-120. E-mail: marciamachado@ufc.br

2 Departamento de Enfermagem. Universidade Federal do Ceará. Fortaleza, CE, Brasil.

3 Research Scientist. Harvard School of Public Health. 677 Huntington Avenue. Boston, MA 02115.

4 Universidade Federal do Rio de Janeiro. Rio de Janeiro, RJ, Brasil.

5,6 Departamento Materno Infantil. Faculdade de Medicina Universidade Federal do Ceará. Fortaleza, CE, Brasil.

\section{Resumo}

Objetivos: identificar as condições sociodemográficas das crianças de 0 a 2 anos de idade nascidas de mães HIV + / AIDS em Fortaleza, Ceará, Nordeste do Brasil.

Métodos: estudo transversal utilizando um questionário semiestruturado com cuidadores (63 mães e 5 avós) de crianças no ambulatório de um hospital estadual, entre Dezembro de 2005 e Abril de 2006.

Resultados: a idade média das mães foi de 26 anos de idade. Aproximadamente $16 \%$ eram analfabetas, $57,3 \%$ eram casadas e $5,9 \%$ viúvas. Mais de dois terços $(79,4 \%)$ das mulheres participantes do estudo tornou-se ciente de seu status de HIV + no último parto e $51,5 \%$ relataram não receber qualquer tipo de assistência social do governo. A idade média das crianças foi de 15,6 meses e 13\% não tiveram um teste de HIV. A maioria delas era proveniente de áreas rurais (60,3\%), com renda familiar média mensal de $R \$ 446,32$. Verificou-se que $57,9 \%$ das crianças viviam em uma casa com cinco ou mais pessoas, $e$ $31 \%$ relataram ter quatro ou mais crianças morando na mesma casa.

Conclusões: há necessidade de estratégias de prevenção e promoção à saúde, levando em consideração o contexto social das famílias que vivem com HIV/AIDS

Palavras-chave Sindrome de imunodeficiência adquirida, Criança, Soropositividade para HIV, Qualidade da assistência à saúde 


\section{Introdução}

Até 2005 foram diagnosticados com Síndrome de Imunodeficiência Adquirida (Aids) aproximadamente 40,3 milhões de indivíduos. Destes, 38,0 milhões são adultos, representados por 17,5 milhões de mulheres e 2,3 milhões por crianças menores de quinze anos de idade. Nesse período, a doença levou a óbito cerca de 3,1 milhões de pessoas, dos quais, 570.000 crianças. ${ }^{1}$ Além disso, em decorrência da Aids, até o final de 1990, no Brasil, 29.929 crianças menores de 15 anos viviam na condição de órfãs. Em 2005, a taxa de mortalidade por Aids no Brasil foi de 6,0/100.000 habitantes. A taxa variou de acordo com a região de residência, mas para o Nordeste chegou a 2,9. Tais indicadores apontam índices persistentes de óbitos nessa região. 2

$\mathrm{O}$ aumento do número de crianças infectadas pelo Human Immunodeficiency Virus (HIV), especialmente nos países mais atingidos pela epidemia, é facilmente perceptível. Em 2002, conforme estimado, 3,2 milhões de crianças até a idade de quinze anos estavam convivendo com o HIV/Aids. Destes, 800.000 eram recém-infectados e 610.000 morreram vítimas da infecção. ${ }^{3}$ As cifras de Aids, até 2005, entre menores de treze anos, somavam 12.014 casos. 4

No Nordeste, a epidemia de Aids encontra-se em franca expansão. Por ser uma das regiões mais pobres do país, esta detém os piores níveis de desenvolvimento socioeconômicos, situação que dificulta as ações de prevenção e controle. Como mencionado por pesquisadores, o comportamento da epidemia nessa região reflete um quadro de desigualdade social a evidenciar que, enquanto se verifica uma desaceleração da epidemia e estabilização na Região Sudeste, no Nordeste há tendência de crescimento.5,6

As crianças vêm constituindo um grupo de risco crescente para a infecção pelo HIV, ao nascer, com nítidos aumentos da incidência de recém-nascidos já infectados. Como medida para interceptar a cadeia de transmissão do HIV de mãe para filho, foi implantado no âmbito do Sistema Único de Saúde um projeto denominado Nascer-Maternidades, com vistas a ampliar o diagnóstico precoce da transmissão vertical (TV). A partir do referido projeto inserem-se como medidas adotadas após o parto o oferecimento gratuito de antirretrovirais e a distribuição de fórmula infantil em substituição ao aleitamento natural, situação contraindicada para mulheres portadoras de HIV/Aids. ${ }^{7}$

No Brasil existem poucos estudos sobre a situação de crianças e adolescentes infectados pelo HIV. ${ }^{8}$ No Ceará, particularmente, não se dispõe de dados sobre esse grupo etário. Diante dessa lacuna, justifica-se a realização desta pesquisa cujo objetivo é identificar as condições sociodemográficas das crianças de zero a dois anos de idade, filhas de mães soropositivas para o HIV, em Fortaleza-CE.

\section{Métodos}

Estudo descritivo, transversal, realizado no Serviço de Assistência Especializada (SAE) do Hospital de Referência Estadual para Doenças Infecciosas do Estado do Ceará, Brasil.

A população do estudo foi constituída por 68 mães ou cuidadoras (avós) de crianças na faixa etária entre zero e dois anos de idade, nascidas de mães soropositivas ao HIV.

Em virtude do serviço não dispor de dados informatizados sobre o número de crianças em seguimento, fez-se uma busca ativa dessa população. Foram entrevistadas mães ou cuidadoras que se dirigiam ao ambulatório médico e odontológico ou que buscavam o serviço para receber antirretrovirais e outros medicamentos. Para recrutar o máximo de participantes, o pesquisador permaneceu nos turnos da manhã e da tarde no serviço, durante o período de novembro de 2005 a abril de 2006. Com estas estratégias, todas as mães ou cuidadoras de crianças que compareceram ao serviço para seguimento no ambulatório de pediatria, para aquisição de medicamentos ou seguimento materno pós-parto foram convidadas a participar do estudo. Destas, apenas uma recusou o convite. Outro componente para encerrar o recrutamento foi a constatação da repetição das mesmas crianças, ou seja, de crianças que já haviam sido abordadas.

Para a coleta de dados utilizou-se um formulário semiestruturado, aplicado por pesquisadores mediante entrevista face a face em uma sala reservada. Dessa forma, buscou-se preservar a intimidade da cliente e a confidencialidade do relato. As pesquisadoras eram enfermeiras, com experiência anterior em pesquisa. Após treinadas pela equipe, fizeram duas entrevistas piloto, previamente ao início do estudo. Os dados foram processados em base eletrônica, no programa Epi Info 6.0, e, para a análise descritiva, procedeu-se à distribuição de frequência das variáveis sociodemográficas das mães e crianças.

Ressalta-se o seguinte: este estudo faz parte de uma ampla investigação aprovada por Comitê de Ética em Pesquisa, sob protocolo 38/2004. Como recomendado, todos os participantes assinaram o termo de consentimento livre e esclarecido, de acordo com as normas da Resolução 196/96 do 
Conselho Nacional de Ética em Pesquisa, sobre pesquisas com seres humanos.

\section{Resultados}

Participaram 68 indivíduos, dos quais 63 mães e 5 cuidadoras avós de crianças, nascidas sob risco de transmissão vertical.

Expõem-se, a seguir, informações sobre as características das crianças nascidas sob o risco de aquisição do HIV. A média de idade das crianças foi 15,6 meses. Em relação ao resultado do exame antiHIV das crianças, no momento da entrevista, referido pelas entrevistadas, $45,6 \%$ apresentavam sorologia negativa para o HIV e $11,8 \%$ HIV positivo, $7,4 \%$ apresentavam indeterminada, $13,2 \%$ aguardavam resultado do exame, enquanto $13,2 \%$ delas não haviam feito a sorologia para detecção do vírus e $8,8 \%$ não sabiam ou não quiseram informar o resultado. Diante desses resultados, não se pode indicar as condições do diagnóstico definitivo dessas crianças, em face da necessidade de observar a evolução sorológica até os dois anos de vida. Neste caso, o estudo indicado é o prospectivo.

A maioria $(60,3 \%)$ das crianças mora em municípios do interior do Estado do Ceará. Segundo se pôde verificar, $73,5 \%$ delas receberam o leite artificial (fórmula láctea) na alta hospitalar e apenas $30,8 \%$ tiveram continuidade do recebimento quando acompanhadas no ambulatório. Entre as crianças beneficiadas pelo recebimento da fórmula láctea na maternidade, $40 \%$ não obtiveram a quantidade adequada do produto.

Quanto ao aleitamento materno, conforme se constatou, 23,6\% das crianças foram amamentadas na sala de parto ou no alojamento conjunto. No entanto, quatro mulheres das que amamentaram não sabiam do diagnóstico de HIV/Aids. Tratando-se do uso de antirretroviral pelas crianças após o parto, $80,6 \%$ delas foram beneficiadas por essa terapêutica. Já a alimentação é oferecida com maior frequência, utilizando-se a mamadeira $(91,2 \%)$.

Sobre as características das mães das crianças (dados maternos de cinco mães foram informados pelas avós das crianças), constatou-se que a idade média materna foi de 26 anos e a renda familiar média de R\$446,32. Segundo observado, $16,2 \%$ das mães não eram escolarizadas e a metade tinha apenas o equivalente ao ensino fundamental.

Entre outros dados das mães pesquisadas, sobressaem os seguintes: a maioria das mães $(79,4 \%)$ teve conhecimento da infecção pelo HIV no último parto, muitas $(57,3 \%)$ eram casadas ou conviviam com seu parceiro, enquanto algumas
$(5,9 \%)$ encontravam-se viúvas. Em consequência dessa situação, quatro crianças eram órfãs. A maioria delas $(67,6 \%)$ autorreferiam ser de cor parda/morena.

No concernente ao trabalho, a maioria era dona de casa, enquanto $27,9 \%$ trabalhavam fora do ambiente doméstico, em emprego fixo. Contudo, $51,5 \%$ delas não contavam com qualquer auxílio social. Quanto à constituição de moradores na casa, 57,9\% coabitavam com mais de cinco pessoas e $30,9 \%$ referiam mais de quatro crianças no mesmo domicílio.

\section{Discussão}

Este estudo apresenta uma proporção elevada de crianças nascidas de mães jovens e soropositivas ao HIV, vivenciando adversidades ante a situação da infecção pelo HIV em decorrência da transmissão vertical. De acordo com informações do sistema de vigilância do Estado do Ceará, de 1983 a 2006 foram notificados 182 casos de Aids em menores de treze anos, sendo $152(83,6 \%)$ casos em decorrência da transmissão vertical. ${ }^{9}$ Neste período, as crianças menores de dois anos integrantes deste sistema representaram $45 \%$ de todos os casos desde o início da epidemia. Como se evidencia, o avanço da Aids no país mostra, ao passar do tempo, novas tendências, entre elas o surgimento de núcleos familiares contaminados pelo HIV.

Embora não fosse objetivo primordial da investigação, à medida que se ampliava o número de mães entrevistadas, revelava-se um aspecto importante de inserção de novos casos em crianças, as quais compartilham lares caracterizados por escassos recursos financeiros. Além disso, essa população não tem acesso aos programas de apoio social, e algumas crianças vivenciam situação de orfandade paterna. Conforme se sabe, a epidemia de Aids impacta a qualidade de vida de crianças e jovens que convivem com a doença, e eles passam por sucessivas perdas, sobretudo com a morte dos pais e, eventualmente, de parentes. 10

Segundo demonstrado por dados da epidemia de Aids, até 2005 houve crescente número de crianças acompanhadas em serviços de saúde especializados em virtude de terem sido geradas e nascidas de mães contaminadas pelo HIV, as quais tomaram conhecimento da infecção antes, durante ou depois da gravidez. Pesquisadores $2,5,11$ registram a tendência da transmissão vertical no país, corroborando essas circunstâncias. Situação semelhante pode estar ocorrendo no Ceará, provavelmente, também, como um reflexo da feminização do HIV, como observado no país. Esta realidade conduz ao risco aumentado da 
transmissão materno-infantil.

Consoante o estudo apontou, a maior parte das mães não amamentou seus filhos, como recomendado para crianças nascidas de mães soropositivas ao HIV. Entretanto, como prevê a recomendação do Ministério da Saúde (MS) para impedir a transmissão vertical, o leite materno deve ser substituído por fórmula láctea (leite em pó) distribuída gratuitamente pelos serviços de saúde. Outra estratégia sugerida é a pasteurização do leite nos bancos de leite humano, mas esta possibilidade não é disponibilizada rotineiramente nos serviços que oferecem este recurso no Brasil.

No estudo ora apresentado, as mães informaram falhas na distribuição e oferecimento da fórmula infantil logo após o parto e nos subsequentes meses do nascimento da criança. Tal situação já divulgada indica problemas operacionais de atenção à saúde das populações contaminadas no Estado do Ceará, principalmente ao binômio mãe-filho.12-14

Diante destas falhas, o uso de leite artificial, indicado para crianças filhas de mães soropositivas, precisa ser acompanhado por uma atenção ambulatorial que proporcione informação e acompanhamento das crianças. Caso contrário pode ocasionar elevado risco de doenças, a exemplo da diarréia e desnutrição, por falta de orientação correta do preparo do produto, especialmente em contextos desprovidos de água potável ou privados das devidas condições socioeconômico-culturais.

A precariedade social a que estão submetidas essas famílias, seja pela baixa renda, número de pessoas habitando no mesmo domicílio, entre outros, pode aumentar a vulnerabilidade dessas crianças às doenças próprias da infância, bem como o risco de atraso no crescimento e desenvolvimento. Como observado, de modo geral, os alimentos são oferecidos em mamadeiras, o que pode facilitar a contaminação do produto durante o manuseio e preparo, bem como evitar o processo de mastigação necessário para o bom desenvolvimento da arcada dentária, além do déficit fonoaudiológico. 15

Estudo avaliando o Projeto Nascer-Maternidade Pública de Fortaleza mostrou pequena parcela de gestantes que iniciaram a terapia antirretroviral no período recomendado e não sabiam informar sobre a sorologia do parceiro. ${ }^{13}$ Embora essa instituição avaliada seja referência para atenção ao HIV/Aids, apenas uma minoria dos profissionais envolvidos com a assistência integral de gestantes recebeu algum tipo de treinamento sobre transmissão vertical. Ainda, segundo revelou o estudo ora citado, os profissionais não realizaram aconselhamento e orientações sobre preparo da fórmula infantil, alimentos e seguimento do recém-nascido, sobre consulta puerperal e adesão ao tratamento.13 Contudo, a assistência dissociada das necessidades das mulheres contaminadas em processo de pósparto repercute diretamente no acompanhamento assistencial inadequado de seus filhos. Neste aspecto, o modelo brasileiro de atenção ao HIV, sobretudo na distribuição gratuita de insumos para tratamento e prevenção, pode estar apresentando problemas de ordem regional-local. Em caso positivo, requer investimentos na avaliação e gerenciamento das ações executadas nos serviços. Provavelmente o que se observou nesse estudo, quanto à irregularidade e à ausência de informações direcionadas à prevenção de HIV/Aids aos filhos de mães contaminadas, seja reflexo de falhas no sistema quanto à prevenção do HIV/Aids no Estado na detecção e no acompanhamento.

Embora no presente estudo não se tenha observado em que idade (mês de vida) houve diagnóstico confirmatório de soropositividade, segundo informação das entrevistadas, $11,8 \%$ das crianças já apresentavam a infecção pelo HIV. No entanto, estudos prospectivos devem ser elaborados para avaliar o diagnóstico definitivo dessas crianças.

Ainda conforme observado, a maioria das mulheres entrevistadas é proveniente do interior do Estado do Ceará, o que corrobora informações da interiorização da epidemia, além de apontar para uma procura de serviços mais especializados para seguimento dessas crianças, apesar da descentralização da assistência adotada no Estado. Talvez isto ocorra porque as entrevistadas são usuárias da mesma instituição e, assim, definem o mesmo serviço para atendimento de seus filhos. Outra hipótese pode estar relacionada ao fato de os pediatras desconhecerem os serviços de atenção oferecidos pelo Estado a essas crianças, ficando as mães sem opção de atendimento.

$\mathrm{Na}$ perspectiva do direito à saúde, todo cidadão pode buscar qualquer serviço, sem obrigatoriedade do seguimento na área adstrita. Entretanto, existem estigmas e preconceitos em relação aos portadores do HIV. Em virtude desses preconceitos, as pacientes escolhem, preferencialmente, lugares considerados mais seguros e adequados para seu seguimento e dos seus filhos. 16

No Ceará, dos 184 municípios, somente 18 $(9,7 \%)$ não haviam notificado a doença até 2005.17 Neste estudo, como se observou, muitas mães se deslocam de municípios distantes da capital para atendimento especializado. Diante desse dado, sugere-se desenvolver pesquisas mais aprofundadas para conhecer os motivos desse deslocamento, a 
despeito de existir serviços especializados no interior do Ceará para atender a essa demanda. Também a pesquisa demonstrou que muitas das mulheres são desempregadas e não recebem auxílio social. Isto pode acarretar mais ônus familiar ao se deslocarem de seus municípios para receber atendimento.

Os programas governamentais (Bolsa Família e Bolsa Escola) representam importantes fontes de subsistência das famílias estudadas. No Brasil, o Programa Nacional de Aids determinou o fornecimento da fórmula infantil às crianças nascidas de mães soropositivas nos serviços de saúde, desde o nascimento até os seis meses de idade, para evitar possível transmissão do vírus pelo leite materno. ${ }^{18,19}$

Contudo, de acordo com dados obtidos no presente estudo, parece não existir normalização nas maternidades públicas para a doação de fórmula infantil, pois $20,6 \%$ das mães entrevistadas não receberam o produto quando da alta hospitalar. Como previsto nas orientações do MS quanto à continuidade da fórmula láctea, nas unidades primárias as mães devem receber a fórmula na quantidade de dez latas por mês, até o sexto mês de vida.7 No entanto, essa distribuição não se mostrou efetiva nos serviços de saúde procurados pelas mães entrevistadas. Tal dado é indicativo de falta de estruturação dos serviços, o que pode dificultar a interação do binômio mãe-filho com o serviço, além de desfavorecer a ingestão de leite pelas crianças nos primeiros seis meses de vida, tornando-as vulneráveis a déficit alimentar.

Conforme identificado, a literatura é escassa em dados sobre as orientações fornecidas às gestantes e puérperas portadoras de HIV/Aids, quanto à alimentação alternativa dos seus filhos. Todavia, alguns estudos divulgam uma série de orientações que possibilitam a atenção a essas mães, facilitando seu aprendizado, além de servirem como guia para os diferentes profissionais que as assistem. ${ }^{12,18}$

De acordo com a Organização Mundial da Saúde (OMS), desde 2001 estabeleceram-se indicadores de atenção integral para pessoas que vivem com HIV/Aids nas Américas. Com base em reuniões com especialistas da área, identificaram-se alguns componentes fundamentais para atenção integral ao HIV/Aids. Entre estas propostas, foram organizadas, como respostas às inúmeras solicitações de autoridades, indicações de melhorias na atenção àqueles que vivem e convivem com HIV. O objetivo é propiciar orientações para formulação de políticas e estratégias necessárias adequadas para satisfazer as necessidades das pessoas que vivem com HIV, de suas famílias e de seus cuidadores. 20

Entretanto, não se observou no presente estudo um ambiente que oferecesse respostas efetivas ao acompanhamento de crianças expostas ao HIV. A ausência no serviço de um protocolo de atendimento sistematizado dessas crianças, provavelmente, pode repercutir nas falhas desse acompanhamento. Conforme se percebe, algumas crianças em seguimento não haviam realizado sorologia para detecção do HIV, situação indicativa da ausência de solicitação ou falta de insumos para diagnóstico laboratorial, condição indispensável para indicar a situação de saúde da criança e, em alguns momentos, diminuir o estresse da mãe diante da espera pelo diagnóstico definitivo da criança.

Para encerrar, ressalta-se a necessidade de realização de novas pesquisas para avaliar as condições de vida das crianças filhas de portadoras de HIV no Ceará, bem como de conhecer o acesso e distribuição dos alimentos na rede pública de saúde e os aspectos da qualidade da atenção oferecida para tais grupos. Destaca-se que, para serem mais eficazes, estratégias de prevenção oferecidas pelos órgãos governamentais, principalmente aqueles ligados à saúde, devem considerar as adversidades das famílias com HIV. Torna-se indispensável auxiliá-las de outras maneiras, não apenas com a distribuição da fórmula láctea nos seis primeiros de vida. É preciso ampliar a ajuda e o seguimento dessas crianças sob o risco de aquisição do vírus. Deve-se considerar, também, as diferentes esferas envolvidas no contexto da Aids na Região Nordeste. Urge oferecer apoio permanente e acompanhamento dessa população vulnerável à morbi-mortalidade, ampliando o seguimento com visitas domiciliares, que deverão ser implementadas pela equipe do Programa Saúde da Família.

\section{Agradecimentos}

Agradecemos ao CT-Saúde/MCT/CNPq/MS (Edital $\left.\mathrm{N}^{\circ} 030 / 2004\right)$, pelo financiamento desta pesquisa, aos profissionais de saúde do Hospital São José e usuárias atendidas no ambulatório. 


\section{Referências}

1. Joint United Nations Programme on HIV/AIDS (UNAIDS) [Acessado em 21 abr 2006]. Disponível em: http://www.unaids.org/en/Resourses/Publications/Corporat + publications/AIDS+epidemic + up + date+December +2005 . asp

2. Brasil. Ministério da Saúde. Boletim epidemiológico AIDS DST Ano III. $1^{\mathrm{a}}$ a $26^{\mathrm{a}}$ semanas epidemiológicas. Brasília, DF; 2005.

3. França-Junior I, Doring A, Stella IM. Crianças órfãs e vulneráveis pelo HIV no Brasil: onde estamos e para onde vamos? Rev Saúde Pública. 2006; 40: 23-30.

4. Brasil. Ministério da Saúde. Boletim epidemiológico AIDS DST Ano III. $1^{\mathrm{a}}$ a $26^{\mathrm{a}}, 1^{\mathrm{a}}$ a $26^{\mathrm{a}}$ semanas epidemiológicas. Brasília, DF; 2006.

5. Brito AM, Sousa JL, Luna CF, Dourado I. Tendências da transmissão de Aids após terapia antirretroviral no Brasil. Rev Saúde Pública. 2006; 40: 18-22.

6. Pascom ARP, Barbosa-Junior A, Szwarcwald CL. Diferenças regionais nas práticas sexuais e comportamentos relacionados à transmissão do HIV. In: Ministério da Saúde (BR). Pesquisa de conhecimentos, atitudes e práticas na população brasileira. Brasília, DF: Ministério da Saúde; 2006. p.65-83.

7. Brasil. Ministério da Saúde. Secretaria Executiva. Coordenação Nacional de DST e AIDS. Projeto nascer. Versão preliminar. Brasília, DF; 2003.

8. Marques HHS, Silva NG, Gutierrez PL, Lacerda R, Ayres JRCM, Dellanegra M, França-Júnior I, Galano E, Paiva V, Segurado AAC, Silva MH. A revelação do diagnóstico na perspectiva dos adolescentes vivendo com HIV/AIDS e seus pais e cuidadores. Cad Saúde Pública. 2006; 22: 61929.

9. Secretaria do Estado da Saúde do Ceará (SESA). Informe epidemiológico - situação epidemiológica da Aids. Fortaleza: SESA; 2009

10. Doring M, Franca Junior I, Stella IM. Factors associated with institutionalization of children orphaned by AIDS in a population-based survey in Porto Alegre, Brazil. AIDS 2005; 19: 59-63.
11. Dourado I, Veras MASM, Barreira D, Brito AM. Tendências da epidemia de Aids no Brasil após a terapia antirretroviral. Rev Saúde Pública. 2006; 40: 9-17.

12. Paiva SS, Galvão MTG. Orientações às gestantes e puérperas portadoras de HIV/Aids quanto à alimentação alternativa dos seus filhos. Nursing. 2006; 95: 782-6.

13. Barroso LMM, Galvão MTG. Avaliação de atendimento prestado por profissionais de saúde a puérperas com HIV/Aids. Texto contexto - enferm. 2007; 16: 463-9.

14. Cavalcante MS, Ramos Júnior AN, Silva TMJ, Pontes LRSK. Transmissão vertical do HIV em Fortaleza: revelando a situação epidemiológica em uma capital do Nordeste. Rev Bras Ginecol Obstetr. 2004; 26: 131-8.

15. Schirmer CR, Fontoura DR, Nunes ML. Distúrbios da aquisição da linguagem e da aprendizagem. J Pediatr. 2004; 80: 95-103.

16. Galvão MTG, Cerqueira ATAR, Marcondes-Machado J. Avaliação da qualidade de vida de mulheres com HIV/Aids através do HAT-QoL. Cad Saúde Pública. 2004; 20: 430-7.

17. Secretaria da Saúde do Estado do Ceará (SESA). Coordenadoria de Políticas e Saúde, Núcleo de Epidemiologia. Aids: informe trimestral. Fortaleza(CE): SESA; 2006.

18. Rea MF, Santos RG, Sanchez-Moreno CC. Quality of infant feeding counseling for HIV+ mothers in Brazil: challenges and achievements. Acta Pediatr. 2007; 96: 94-9.

19. Brasil. Ministério da Saúde. Manual normativo para profissionais de saúde de maternidades da iniciativa Hospital Amigo da Criança - Referência para mulheres HIV positivas e outras que não podem amamentar. Brasília, DF; 2004

20. Organização Panamericana de Saúde. Atención integral por escenarios de atención y niveles: pautas de atención integral para personas que viven com VIH/SIDA em las Américas. Informe reduzido. Genebra; 2001.
Recebido em 6 de abril de 2010

Versão final apresentada em 11 de maio de 2010

Aprovado em 31 de maio de 2010 